\title{
DIMENSÕES HISTÓRICAS DA MATEMÁTICA
}

\author{
Dinazilda Idalêncio Konan ${ }^{1}$ \\ Luiz Carlos Farias Araujo ${ }^{2}$
}

\section{Resumo}

Esta pesquisa tem como objetivo retratar sobre as dimensões históricas da matemática, destacandose o contexto histórico do ensino da matemática; a matemática nos parâmetros curriculares; a matemática e a construção da cidadania; e a matemática e a Base Nacional Comum Curricular. Ao chegarem ao Brasil, os Jesuítas dedicaram-se à pregação da fé católica, destacando-se no trabalho educativo e no ensino das primeiras letras. As Escolas Jesuítas se expandem por todo o Brasil, com práticas que destinavam pouquíssimo tempo às matemáticas. Após a primeira e segunda Guerras Mundiais, as crianças passaram a ter acesso à escola, entretanto a educação matemática continuava seguindo os métodos tradicionais de ensino. Algumas mudanças no ensino da Matemática correlaciona-se diretamente ao movimento Anísio Teixeira na década de 30 cujo estudo da matemática nessa época estava embasado no raciocínio dedutivo do grego Euclides. O referido trabalho foi desenvolvido com base em pesquisa bibliográfica com a finalidade de construir um embasamento teórico. Conclui-se que durante muito tempo as aulas tradicionais persistiram e com ela os problemas. Após a década de 30 e com a Guerra Fria, os avanços tecnológicos fizeram com que os norte-americanos se interessassem pela formação de novos cientistas nas escolas e para isso, formularam um novo currículo para a matemática.

Palavras-chave: contexto histórico. Ensino. Matemática.

\begin{abstract}
This research aims to portray the historical dimensions of mathematics, highlighting the historical context of mathematics teaching; mathematics in curriculum parameters; mathematics and the construction of citizenship; and mathematics and the Common Base National Curriculum. Upon arriving in Brazil, the Jesuits dedicated themselves to the preaching of the Catholic faith, standing out in their educational work and in teaching the first letters. Jesuit Schools expand throughout Brazil, with practices that devote very little time to mathematics. After the first and second World Wars, children began to have access to school, however mathematical education continued to follow traditional teaching methods. Some changes in the teaching of Mathematics are directly correlated to the Anísio Teixeira movement in the 1930s whose study of mathematics at that time was based on the deductive reasoning of the Greek Euclides. This work was developed based on bibliographic research in order to build a theoretical foundation. It is concluded that for a long time the traditional classes persisted and with them the problems. After the 1930s and with the Cold War, technological advances made the Americans interested in the formation of new scientists in schools and for that, they formulated a new curriculum for mathematics.
\end{abstract}

Keywords: historical context. Teaching. Mathematics.

\footnotetext{
${ }^{1}$ Graduada em Matemática pela Universidade Federal da Bahia - UFBA. Graduada em Direito pela Faculdade 2 de Julho. Especialista em História da Matemática pela Faculdade Innovation. Especialista em Construção do Raciocínio Lógico- pela Faculdade Innovation; Professora de Matemática da Rede Estadual da Bahia. Advogada do Escritório IK advogados associados. Email: dinakonan@gmail.com.

2 Mestre em Ciências da Educação pela Faculdade Internacional de Ciências Sociais (FICS). Licenciado em Matemática pela Universidade Católica do Salvador (UCSAL). Especialista em Metodologia da Matemática pela Faculdade Internacional de Curitiba (FACINTER). Especialista em Matemática e Física, pela Faculdade Internacional de Curitiba( Grupo UNINTER). Email:
} 


\title{
Introdução
}

Esta pesquisa tem o objetivo de apresentar um panorama histórico do ensino da matemática. Ao chegarem ao Brasil, os Jesuítas dedicaram-se à pregação da fé católica, destacando-se no trabalho educativo e no ensino das primeiras letras. Além do curso elementar, eles mantiveram os cursos de Letras e Filosofia, considerados secundários, e curso de Teologia e Ciências Sagradas, de nível superior, para formação de sacerdotes. Inicialmente, as Escolas Jesuítas eram para o ensino de jovens imigrantes portugueses. Depois começam a aceitar filhos de outros imigrantes e mais tarde também índios e mestiços. Neste momento, aconteceu uma verdadeira revolução na pedagogia:

\begin{abstract}
Ao exigir do processo educativo uma preocupação com o estudo da criança e a valorizar a educação como um processo que partia dos objetos sensíveis aos objetos intelectuais contribuindo para uma mudança pedagógica no que diz respeito às finalidades e aos métodos educativos (BERTI, 2009, p. 11).
\end{abstract}

As Escolas Jesuítas se expandem por todo o Brasil, com práticas que destinavam pouquíssimo tempo às matemáticas. Paralelo a esses acontecimentos o mundo vivia um clima de mudanças em torno da educação e os métodos utilizados no ensino. Esse ensino forneceu as bases educação atual, ao propor uma educação não repressiva voltada ao desenvolvimento da criança, pautados na curiosidade e interesse, que caminhasse do concreto ao abstrato, da intuição ao conceito, que substituísse a tradição pela experimentação. Johann Pestalozzi (17461827), influenciado pelo processo educativo, entre os fins dos séculos XVIII e começo do XIX passou:

A dar grande importância à psicologia e na formação de professores. No Brasil, a partir de 1920, as discussões sobre as reformas educacionais ganharam amplitude jamais vista no país, onde estavam, em pleno fervor, de um lado as ideias pedagógicas da Escola Nova, que dava grande valor à psicologia, e de outro, os influentes educadores católicos a favor da manutenção da Pedagogia Tradicional (lbid., p. 16).

Embora, tendo origem nos movimentos da burguesia e da classe média, as propostas de mudanças educacionais da Escola Nova era um grande avanço porque propunham 'métodos ativos ${ }^{3}$ de ensino aprendizagem; deu importância à liberdade da criança e ao interesse do educando; adotou métodos de trabalho em grupo;

\footnotetext{
${ }^{3}$ Processo de ensino em que os estudantes ocupam o centro das ações educativas por meio da problematização da realidade, como estratégia pedagógica.
} 
incentivou a prática de trabalhos manuais nas escolas; valorizou os estudos de psicologia experimental; e procurou colocar a criança, no centro do processo educacional descentralizando o professor.

O ensino da Matemática correlaciona-se diretamente ao movimento Anísio Teixeira na década de 30 que propôs ao Distrito Federal, reformas onde se preocupava com a orientação dada com relação à questão dos problemas aritméticos, destacando:

\begin{abstract}
Que as condições dos problemas deveriam ser as mesmas da vida real. As premissas para proposição de problemas devem estar de acordo com as ocupações e interesse da classe, a fim de que os alunos, sentindo a necessidade de resolvê-los, se dediquem à solução, movidos por interesse legitimo. Assim as contas que a criança faz para casa, no mercado, na feira, nas lojas, no armazém; os trabalhos escolares, movimento de cooperativas, jogos, esportes, excursões; a saúde da criança e de pessoas da família, as condições de saúde do bairro, incluindo serviços de saúde pública, despesas com receitas, dietas, remédios etc., fatos diversos que a criança presencia - tudo isso constitui assunto para problemas (MIORIM, 1998, p.90)
\end{abstract}

Entretanto, matemáticos de todo o mundo, pensavam uma atualização para o ensino da matemática onde a inquietação com o ensino constituído na introdução da concepção de função, elemento unificante dos diversos divisões da Matemática.

Esse pensamento já representava uma tentativa de adequação do ensino aos estudos mais atualizados no campo da Matemática, que tinham como uma de suas características quebrarem as barreiras existentes entre os campos matemáticos Aritmética, Álgebra e Geometria. Esse movimento estava de certa forma se organizando para o Movimento da Matemática Moderna que viria acontecer futuramente.

\title{
Contexto Histórico do Ensino da Matemática
}

A história da colonização do Brasil está intrinsecamente relacionada à formação das Forças Armadas Brasileira, que inicialmente composta apenas pela Marinha e Exercito tem origem nas tropas portuguesas no período da colonização, sendo integrada posteriormente e mais recentemente pela Aeronáutica.

Esse início militarizado devido à necessidade de defender a Coroa Portuguesa em suas conquistas de território gera a necessidade de instrução de seus militares que estavam morando no Brasil, possibilitando a edificação de fortes e o desenvolvimento da artilharia. Data desse período a criação das primeiras obras 
voltadas para essa formação que envolvia conhecimentos elementares de aritmética e geometria (MIORIM, 1998).

Logo após, a proclamação da independência do Brasil em relação a Portugal, ficou evidente a necessidade de outra independência que pudesse estabelecer uma autonomia intelectual mínima, ficando, assim, estabelecido a criação do ensino de Direito em terras brasileiras, criação que foi impulsionada devido aos acontecimentos políticos. Que na realidade foi uma porção escolhida:

Da grande família brasileira, a mocidade a quem um nobre estímulo levou à Universidade de Coimbra, geme ali debaixo dos mais duros tratamentos e opressão, não se decidindo, apesar de tudo, a interromper e a abandonar sua carreira, já incertos de como será semelhante conduta avaliada por seus pais, já desanimados por não haver ainda no Brasil institutos onde prossigam e rematem os seus encetados estudos (VAMPRÉ, 1924. p.1011).

Percebe-se que os estudantes brasileiros que cruzavam o Atlântico para cursar Direito na Universidade de Coimbra passaram a ser oprimidos e hostilizados pelos cidadãos locais que não estavam habituados com a recente autonomia. Um projeto de lei apresentado em 19 de agosto de 1823, que determinava a criação de duas Universidades, quais sejam, o primeiro curso jurídico na novíssima Nação independente: uma em Olinda e outra em São Paulo. A partir da criação das Universidades em território brasileiro houve a necessidade da criação de cursos preparatórios para o ingresso nas mesmas. Nesse momento, se inicia:

\footnotetext{
A criação de cursinhos preparatórios para o ingresso em cursos superiores e com a criação do Colégio Pedro II as primeiras tentativas de criação do ensino fundamental. Entretanto, como os cursinhos preparatórios eram o caminho mais curto para passar nos exames de ingresso, em geral havia um grande abandono do colégio (VALENTE, 2008. pp 11-23).
}

Nesse sentido, os cursinhos preparatórios foram criados tendo apoio de militares e incluíram exames de geometria na admissão. Assim, o conteúdo dos exames se tornaram a primeira referência curricular, que era o mesmo oferecido nos cursos preparatórios. As primeiras faculdades de filosofia surgiram em 1930, com o intuito de formação de professores. Com isso, foi sendo implantado o ensino seriado obrigatório. Graças aos esforços de Euclides Roxo, na Reforma Francisco Campos, funde-se, as, então, disciplinas de aritmética com a álgebra e a geometria, transformando-as na disciplina de matemática (MARTINS, 2009). 
Observa-se, entretanto, que as disciplinas não se fundem, pois, as matérias continuavam sendo ensinadas separadamente. Na década de 1960, surge com força o movimento da Matemática moderna, baseando o ensino de matemática na formalidade e no rigor. A Revolução Industrial, que acontece no final do século XVIII, exige das pessoas um entendimento de administração, produção e sistemas bancários, propiciando a aplicação da matemática na sala de aula, sendo que nem sempre essa matemática ensinada nas escolas da época era adequada para a faixa etária dos alunos.

O estudo da matemática nessa época estava embasado no raciocínio dedutivo do grego Euclides (séc. III a.C.) que utilizava linguagens inadequadas para iniciar a disciplina na educação básica e apenas:

\footnotetext{
Após a Primeira Guerra Mundial, com a chegada dos imigrantes e o início da industrialização começou a aparecer uma maior preocupação com a escola. Entretanto de forma mais concreta, somente a partir dos anos 60, do século XX, a partir de movimentos populares, de mobilização sindical se concretizaram as primeiras experiências de popularização da escola (CARNEIRO, 2008, p. 1).
}

Após a primeira e segunda Guerras Mundiais, as crianças passaram a ter acesso à escola, entretanto a educação matemática continuava seguindo os métodos tradicionais de ensino. Assim, não poderia ter outro resultado, a não ser, um grande número de reprovação e aversão à disciplina, pois o ensino da matemática tradicional era distante da realidade do aluno e não possuía aplicação prática.

Durante todo o século $X X$, as aulas tradicionais persistiram e com ela os problemas. Após a década de 30 e com a Guerra Fria, os avanços tecnológicos fizeram com que os norte-americanos se interessassem pela formação de novos cientistas nas escolas. Para isso, formularam um novo currículo para a matemática, que foi nomeada como Matemática Moderna e que não foi seguida adiante por falta de didática, não era viável o seu estudo para os alunos do ensino fundamental (MIRANDA, 2003).

Os professores que hoje se dedicam ao ensino da matemática nas escolas se preocupam com a sua finalidade e a forma como se ensina, pois, desta forma, será melhor o conhecimento da ciência matemática. Ou seja, não se preocupam com a matemática pura, pela sua beleza e grau de abstração e, sim, com uma matemática prática que se aplique aos problemas cotidianos. A história do ensino dessa ciência 
nos conta que essa preocupação já se encontrava entre os séculos VI e IV a.C. E nesse momento passou então a existir duas Matemáticas: uma intelectual e outra manual.

Após essa divisão, profundas mudanças trouxeram, como consequências, a priorização dos estudos teóricos e a desvalorização das aplicações práticas e que vieram a influenciar todo o desenvolvimento futuro da matemática e de se seu ensino. No Brasil, as tendências mundiais são acompanhadas, e a crescente preocupação com a modernização do ensino da matemática tinha por base a Matemática Euclidiana considerada arcaica, frente aos novos avanços dessa ciência, como os modernos métodos do cálculo infinitesimal.

A identificação da Educação Matemática como uma área prioritária na educação ocorre na transição do século XIX para o século XX e nessa época, a Educação Matemática, era sinônimo de boa didática, cumprimento dos programas e verificação da aprendizagem de conteúdos através de exames 4 rigorosos. Considerando a ampliação do ensino às classes trabalhadoras com a universalização da educação e a relação educação-trabalho passam a ser os grandes temas das discussões educacionais.

\section{A Matemática nos Parâmetros Curriculares}

Ao longo dos tempos o ensino da Matemática tem passado por sucessivas reformas. Mesmo assim, o fracasso escolar matemático continua. No momento em que as Secretarias Municipais e Estaduais de Educação se esforçam para absorver e se adequar às novas normas vigentes, os Parâmetros Curriculares Nacionais (PCN's) desempenham importante papel, pois:
O ensino da Matemática tem passado, ao longo dos anos, por sucessivas reformas. A Matemática deverá ser vista pelo aluno como um conhecimento que pode favorecer o desenvolvimento do seu raciocínio, de sua sensibilidade expressiva, de sua sensibilidade estética e de sua imaginação (BRASIL, 1997, p. 14).

Os conceitos básicos contidos nos Parâmetros Curriculares Nacionais em Matemática refletem muito mais do que uma mera mudança de conteúdos, uma mudança de filosofia de ensino e de aprendizagem. Direcionam para a necessidade de mudanças não apenas no que ensinar, mas, principalmente em como ensinar, avaliar e como organizar as situações de ensino e de aprendizagem. É destacado o papel da matemática no ensino fundamental como meio facilitador para a estruturação e o desenvolvimento do pensamento do discente e para a formação 
básica de sua cidadania. É importante que a Matemática desempenhe, equilibrada e indissociavelmente, seu papel na formação de capacidades intelectuais:

$\mathrm{Na}$ estruturação do pensamento, na agilização do raciocínio dedutivo do aluno, na sua aplicação a problemas, situações da vida cotidiana e atividades do mundo do trabalho e no apoio à construção de conhecimentos em outras áreas curriculares. Falar em formação básica para a cidadania significa falar em inserção das pessoas no mundo do trabalho, das relações sociais e da cultura, no âmbito da sociedade brasileira (Ibid., p.25-29).

Ao abordar sobre à pluralidade étnica brasileira, à heterogeneidade e a fortuna do conhecimento matemático que o discente leva para a sala de aula, destaca-se nos PCN's que o ensino da Matemática, a par do reconhecimento da importância da pluralidade sociocultural do aluno pode contribuir para a perspicácia do seu espaço social e para sua participação ativa na transformação do seu meio.

Os conteúdos aparecem organizados em blocos, diferentemente do modo tradicional, a saber: números e operações (aritmética e álgebra); espaço e formas (geometria); grandezas e medidas (aritmética, álgebra e geometria); tratamento da informação (estatística, combinatória e probabilidade). Fica evidente, a orientação de se pensar e de se organizar as situações de ensino-aprendizagem quando favorece ou:

Privilegia as chamadas intraconexões das diferentes áreas da Matemática e as interconexões com as demais áreas do conhecimento, o que entendo como um caminho possível e desejável para o ensino da Matemática. As intraconexões defendem uma visão mais integrada, menos fragmentada da Matemática. Algumas orientações didáticas são colocadas ao (à) professor (a), através de exemplos práticos, mostrando que é possível interligar Aritmética com Álgebra ou Aritmética com Geometria e Álgebra, numa mesma atividade (BRASIL, 1997, p.97-133).

No outro lado, estão as interconexões, que têm nos Temas Transversais ética, saúde; meio ambiente; pluralidade cultural e orientação sexual - uma infinidade de possibilidades de se concretizarem. Para tanto, é importante que o docente desenvolva suas atividades em sala de forma interdisciplinar unificando uma equipe de parcerias com outras disciplinas (GATTI, 2010). A influência mútua com seus colegas consentirá que os projetos desenvolvidos sejam mais simpáticos e mais voltados a problemas da realidade.

De acordo com os PCN's, os objetivos para o Ensino Fundamental de forma resumida é promover ações para que o discente possa compreender a transformar o mundo ao seu redor; estabelecer afinidades e resolver situações-problema; comunicar-se de forma matemática; estabelecer as intraconexões matemáticas e as 
conexões com as outas disciplinas; desenvolver sua autoconfiança no seu fazer matemático; e interagir adequadamente com seus pares.

A Matemática pode colaborar para o desenvolvimento de novas competências, novos conhecimentos, para o desenvolvimento de diferentes tecnologias e linguagens que o mundo globalizado exige das pessoas, para tal:

O ensino de Matemática prestará sua contribuição à medida que forem
exploradas metodologias que priorizem a criação de estratégias, a
comprovação, a justificativa, a argumentação, o espírito crítico e favoreçam
a criatividade, o trabalho coletivo, a iniciativa pessoal e a autonomia advinda
do desenvolvimento da confiança na própria capacidade de conhecer e
enfrentar desafios (BRASIL, 1997, p.31)

Destaca-se, ainda, a necessidade de entender a palavra conteúdo nos PCN's, que não devem ser entendidos como uma listagem, basicamente em três extensões: concepções, metodologias e costumes. Valoriza-se, assim, muito mais a compreensão das ideias matemáticas e o modo como estas serão procuradas (podendo esse modo de procura ser estendido e aplicado para as demais áreas do conhecimento) do que a sua sistematização, muitas vezes vazia de significado.

Entendem-se os conteúdos como um meio para desenvolver atitudes positivas diante do saber em geral e do saber matemático em particular. O gosto pela matemática e o incentivo a procedimentos de busca exploratória, desenvolvendo uma atitude investigativa diante de situações-problema propostas pelo docente são alguns exemplos dessa compreensão mais ampla do que é ensinar e aprender em Matemática.

Nos PCN's há avanços importantes, sendo necessário entender os parâmetros como tal e não como uma listagem de conteúdos. Mais preocupante, porém é saber como preparar convenientemente o docente para essas mudanças. Parece ficar cada vez mais evidente a necessidade de propiciar ao (à) professor (a) vivências pessoais de aprendizagem matemática e de promover a metacognição ${ }^{4}$, consciência do seu pensar, no decorrer dessas vivências, tornando-as prazerosas (PCN, 1998).

A estrutura dos PCN's poderá ser compreendida, permitindo que novas abordagens sejam introduzidas e outras sejam mantidas ou modificadas. O curso de formação continuada tem sido requerido, demonstrando que, apenas por meio dessas estratégias, é que poderão acontecer progressos reais no ensino

\footnotetext{
${ }^{4}$ Capacidade do indivíduo de monitorar e autorregular os próprios processos cognitivos.
} 
fundamental. Cabe aos docentes de matemática envolvidos na formação e na educação continuada do docente contribuir para um melhor entrosamento e, por conseguinte, para o emprego apropriado das orientações inseridas nos mesmos, evitando, uma possível falha de uma sugestão que apresente novidades extraordinárias, por ser mal decifrada e/ ou mal-empregada em sala de aula.

A matemática entra no programa das escolas no final do século XVIII, com a Revolução Industrial, entretanto currículo e livros didáticos são criados com base na formalização e no raciocínio dedutivo do grego Euclides (séc. III a.C.), decisivo para compreender a matemática, mas inadequada para aulas no ensino básico.

Durante as guerras mundiais (séc. XX), a Matemática evolui e adquire importância na escola, mas continua distante da vida do discente. Nos dias atuais, as crianças, jovens e/ou adultos chegam às salas e aumenta o desânimo de dificuldades na aprendizagem de matemática. $O$ aproveitamento cai, a disciplina passa a ser a maior causa de reprovação. Mesmo assim, a formalização ainda persiste. E para minimizar tal situação surgiu a matemática moderna, com uma proposta de melhoria na aquisição $e$ assimilação de conteúdos para o discente apoiada na teoria dos conjuntos, mantendo o foco nas metodologias e isolando a geometria.

Anos mais tarde inicia o Movimento de Educação Matemática, com a participação de docentes do mundo todo reunidos em grupos de estudo e pesquisa. Especialistas desvendam como se estabelece o conhecimento das crianças e pesquisam novas possibilidade de avaliação. E neste momento surgem divergências entre os especialistas ligados à educação e se dividem entre os que apoiam e os que resistem às mudanças.

Nos anos 90, são lançados no Brasil os Parâmetros Curriculares Nacionais e liderados pelos integrantes brasileiros do Movimento de Educação Matemática redigem o capítulo dedicado à disciplina de matemática. $E$, atualmente, mesmo com o surgimento da Base Nacional Comum Curricular - BNCC, os PCN's ainda são as melhores ferramentas para nortear os professores que querem modificar sua maneira de ministrar aulas e, com isso, minimizar o fracasso escolar. Como componente importante na construção da cidadania no PCN a matemática traduz: 
é, à apreensão do significado; aprender o significado de um objeto ou acontecimento pressupõe vê-lo em suas relações com outros objetos e acontecimentos (BRASIL, 1997, p. 58).

A aprendizagem da matemática está intimamente ligada a cidadania no sentido que a mesma é um meio para o exercício da cidadania e não é possível conceber o ensino e aprendizagem de matemática desligado da realidade social em que se vive.

\title{
A Matemática e a Construção da Cidadania
}

A formação do cidadão é um resultado de modelos unificados de admissão ao ensino e aprendizagem, cuja prática de cidadania ficaria limitada a um mero cumprimento de atividades e exercícios matemáticos. Entretanto, nos dias atuais a educação matemática como uma grande área de pesquisa, tem procurado desmistificar de modo crítico a interpretação atribuída no ensino e, conduzida pelo livro didático, das propostas dos PCN's e de entendimentos de matemática incorporadas na escola.

Concepções estas no que concerne à ideia de um conhecimento apenas prático e utilitário ou, prioritariamente, técnico e abstrato, e às consequências destes enfoques na formação do cidadão e educação para a cidadania. A matemática precisa ser usada para a vida proporcionando condições para que os alunos:

\begin{abstract}
Saibam usar a matemática para resolver problemas práticos do cotidiano; para modelar fenômenos em outras áreas do conhecimento; compreendam que a matemática é uma ciência com características próprias, que se organiza via teoremas e demonstracõos; percebam a matemática como um conhecimento social e historicamente construído; saibam apreciar a importância da matemática no desenvolvimento científico e tecnológico (BRASIL, 2006, p. 69).
\end{abstract}

A matemática deve ser usada na construção de valores na formação do cidadão. Ela está entrelaçada com a história da civilização, enquanto uma área específica de conhecimento e, configura-se desde os seus primórdios, como uma produção humana lapidada ao longo do tempo. Nesse sentido, movimentos que permitiram o desenvolvimento desse conhecimento, seguiram caminhos diferentes em variadas culturas. O modelo reconhecido e conduzido até os dias de hoje no Ocidente, originou-se com a civilização grega abrigando sistemas formais e estruturados logicamente mediados por um conjunto de premissas e regras de raciocínio (MOL, 2013). Na realidade o problema é que: 
Há inúmeros argumentos, sobretudo cifras e estatísticas, para apoiar opiniões perfeitamente divergentes. Por todas estas razões, parece fundamental reconhecer a influência que pode apresentar o conhecimento matemático na sociedade e na vida do cidadão, pois de um lado, há um apelo permanente à sua aplicação nas mais diversas e variadas atividades e, de outro, há implicitamente um jogo de crenças, mitos e valores, isto é, que confirmam para este conhecimento ideias de rigor, precisão e, muitas vezes, verdade (CANIVEZ, 1991, p.105).

Essa dicotomia entre uma concepção de matemática utilitária e formal no ensino pode ser observada por meio das propostas de conteúdos e exercícios. Pesquisadores em educação matemática parecem confirmar determinadas tendências ainda presentes no ensino de matemática no que diz respeito à maneira de conceber o conhecimento matemático, incentivando uma determinada formação de cidadão porque "ainda predominam no ensino de matemática, concepções de conhecimento relacionadas aos fundamentos da matemática, dogmas - padrão, o platonismo, o formalismo e o construtivismo" (PIRES, 2000, p.62).

O platonismo compreende o corpo de conhecimentos matemáticos como entidades imutáveis e independentes da realidade vivida, revelando uma concepção estática e de descoberta de matemática no ensino. O formalismo concebe a matemática como um conjunto de axiomas, propriedades e demonstrações lógicas a partir da experiência do matemático. Finalmente, o construtivismo entende a matemática obtida por uma construção finita. E nas propostas atuais, educadores e matemáticos:

Colocam a atividade matemática como criação, produção, fabricação, não mais como olhar e desvelar. Enfatizam que os conceitos matemáticos não são um bem cultural, transferidos como herança em forma de dom ou socialmente como capital cultural, e sim o resultado de um trabalho da estruturação do pensamento: o dos matemáticos, no curso da história, e do aluno, no curso de sua aprendizagem (Ibid., p. 63).

Este olhar do construtivismo agora na atualidade parece conceber a matemática como um conhecimento que leva em conta sua história e produção pela humanidade, assim, como todo conhecimento, o que parece indicar um olhar que se contrapõe com as concepções platônica e formalista. Em matemática, por exemplo, os números e as operações, as equações, as frações foram criados num determinado tempo, por alguma razão e respondendo por uma convenção ou, até mesmo, imposição.

Sobre a influência da matemática na formação do aluno, observa-se duas concepções acerca do ensino de matemática, as quais são sustentadas pelos professores: "primeiro, a matemática desenvolve o raciocínio lógico dos alunos e, 
segundo, a matemática está presente no quotidiano dos alunos" (ROCHA, 2001, p.25).

O argumento do raciocínio lógico remete formalismo, ao conceber o conhecimento matemático ligado diretamente a fórmulas, regras no ensino com práticas que privilegiam conteúdos com um auto grau de abstração sem ligação com a realidade quando, por exemplo, em particular nas SIEF5, há uma ênfase exagerada em trabalhar apenas com listas de exercícios sempre iguais de expressões numéricas extensas, frequentemente com operações e cálculos de forma isolada, racionalizações de denominadores e operações entre frações de forma abusiva.

A consequência deste olhar da matemática no ensino tem como consequência a formação de um cidadão passivo e alienado, pois automatiza suas ações e respostas. Por outro lado, a ideia de uma matemática relacionada ao quotidiano surge como uma alternativa no ensino bastante enfatizada atualmente nas escolas. Esse caráter utilitário da matemática desenvolve-se a partir de situações - problema envolvendo cálculos variados, conectados com a realidade social, ou do contexto, e articulados com outras áreas de conhecimento.

Visto assim, a matemática no ensino pode estimular uma formação de cidadão ativo quando a situação-problema incentiva o sujeito a pensar e a utilizar as ferramentas matemáticas de muitas maneiras, tais como, procurar diferentes alternativas para a resolução, relacionar a matemática com outras áreas, ou a realidade vivida, e introduzir discussões que estimulem questionar valores e validar diferentes pontos de vista.

Embora a ideia de cidadania apresentada pelos conjuntos dos PCN's pareça se limitarem à questão de uma educação de direitos e deveres individuais, formalmente, tais propostas orientadas para a área de matemática, se de fato, assim trabalhadas no ensino, podem oportunizar o diálogo, a discussão, abarcar diferentes opiniões, incorporar valores pautados na solidariedade e no respeito, além de fornecer o conhecimento matemático como possibilidade de ação e participação do sujeito.

Qual o significado de identificar a cidadania no ensino escolar relacionada com o saber matemático enquanto um conhecimento ou ferramenta essencial a

\footnotetext{
${ }^{5}$ Séries Iniciais do Ensino Fundamental, ou Ciclos Iniciais do Ensino Fundamental, nomenclaturas geralmente utilizadas para se referir aos Anos Iniciais do Ensino Fundamental.
} 
questionar e agir na sociedade. Tais expectativas podem induzir na educação escolar, uma prática de cidadania ativa (CANIVEZ, 1991).

No caso, as propostas dos PCN's relacionando a matemática e a cidadania não se caracterizam apenas pelo reconhecimento e distribuição de direitos e deveres, mas pela aquisição de determinadas habilidades no ensino que dependendo da forma que são exploradas podem estar voltadas para estrutura mudanças na sociedade ou apenas para adaptar o cidadão no modelo capitalista e competitivo de sociedade.

Sendo assim, parece importante uma determinada prevenção quanto às proposições de uma concepção utilitária ou pragmática de matemática trazida pelos PCN's dos $1^{\circ}$ e $2^{\circ}$ ciclos, sobretudo, quando compreendem o conhecimento matemática como uma ferramenta para a formação do cidadão, sugerindo que "para exercer a cidadania é necessário saber calcular, medir, raciocinar, argumentar, tratar informações estatisticamente, etc" (BRASIL, 1997, p.30).

O desenvolvimento de tais habilidades pode estar incentivando apenas sujeitos preparados para o mundo do trabalho e da competitividade, distanciados dos questionamentos da luta por direitos. Entretanto, a união dos temas transversais voltados para a matemática, objetivando oportunizar práticas que envolvem o diálogo, o respeito por diferentes culturas e dialogar com outras fontes do saber, pode permitir transcender esta concepção pragmática de conhecimento no ensino da matemática.

Nesse mesmo sentido, a proposição no ensino de estratégias - recursos como a resolução de problemas, a história da matemática, as tecnologias da informação e jogos de matemática - sob o olhar, dos PCN's, sugerem que o conteúdo a ser estudado "esteja vinculado a uma aplicação prática, mas também contemple o desenvolvimento de atitudes e valores para a possibilidade de tornar os alunos cidadãos críticos e conscientes" (BRIGUENT e MARENI, 2003, p.127).

\section{A Matemática e a Base Nacional Comum Curricular}

A Matemática quando trabalhada de forma contextualizada e interdisciplinar, se apresenta como um campo curricular fascinante, diferentemente de como se constitui para algumas áreas de conhecimento complexa. Desse modo, democratizar sua aprendizagem na escola deve ser o papel do professor. 
A partir de um documento denominado Base Nacional Comum CurricularBNCC, surgiram reflexões sobre um currículo nacional. Entretanto, entende-se que essa discussão sobre o que aprender, está envolta a um currículo como prática de poder. Nessa disputa curricular a BNCC se apresenta como:

Um documento de caráter normativo que define o conjunto orgânico e progressivo de aprendizagens essenciais que todos os alunos devem desenvolver ao longo das etapas e modalidades da Educação Básica, de modo a que tenham assegurados seus direitos de aprendizagem e desenvolvimento (BRASIL, 2016, p. 05)

O direito de aprender é fundamental, e a aprendizagem como qualidade deve ser a meta principal da escola, fomentada pelo governo. A BNCC propõe o direito de aprendizagem e desenvolvimento dos componentes curriculares estabelecidos para todos com a superação da fragmentação do conhecimento, o estímulo à sua aplicação no cotidiano.

A BNCC visa promover o protagonismo do aluno em sua aprendizagem e a importância do contexto para dar sentido ao que se aprende. Sobre essa fundamental importância da educação, e, por conseguinte, do direito de aprender na concepção de que:

O direito à educação parte do reconhecimento de que o saber sistemático é mais do que uma importante herança cultural. Como parte da herança cultural, o cidadão torna-se capaz de se apossar de padrões cognitivos e formativos pelos quais tem maiores possibilidades de participar dos destinos de sua sociedade e colaborar na sua transformação. Ter o domínio de conhecimentos sistemáticos é também um patamar sine qua non ${ }^{6}$ a fim de poder alargar o campo e o horizonte destes e de novos conhecimentos (CURY, 2002, p. 247).

Ter propriedade de noções ordenados através de um instigante trabalho, na proposta curricular voltada para o pleno desenvolvimento do educando que permite a concretização o pleno desenvolvimento do educando, no preparo para o exercício da cidadania. A missão principal é somar esforços pela construção de uma educação cada vez melhor, integrando os interesses e necessidades do nosso público alvo, o alunado. O educando é um ser pensante, crítico e formador de opiniões, capaz de exercer sua cidadania como um ser construtivo do processo social.

$\mathrm{Na} \mathrm{BNCC}$, os objetos de conhecimento e conteúdos de matemática são distribuídos em unidades temáticas, colaborado com o currículo de matemática,

\footnotetext{
${ }^{6}$ Extremamente importante, essencial.
} 
especialmente, para a matemática dos anos iniciais do ensino fundamental, considerando nesse contexto o direito de aprender a partir do desenvolvimento das habilidades. Sobre essa abordagem:

\begin{abstract}
Existe uma discussão no entorno das questões curriculares que envolvem a BNCC a partir de uma reflexão sobre os objetos de conhecimento e conteúdos de matemática nos anos iniciais do ensino fundamental além de discutirmos as reformas educacionais curriculares (BRASIL. 2017, [s.p.])
\end{abstract}

Assim, para o enfrentamento das demandas exigidas, percebe-se a necessidade de discutir a BNCC, mais especificamente, os conteúdos de matemática, e a participação do professor na construção desse documento que tem como objetivo redimensionar a proposta curricular nas escolas.

Para refletir os objetos de conhecimento matemáticos que influenciarão diretamente nos processos de ensino e de aprendizagem na educação básica é importante analisar a BNCC especialmente, no que tange o ensino fundamental, acerca dos conteúdos de matemática, por que:

\begin{abstract}
Sobre o conhecimento matemático a BNCC considera que é necessário para todos os alunos da Educação Básica, seja por sua grande aplicação na sociedade contemporânea, seja pelas suas potencialidades na formação de cidadãos críticos, cientes de suas responsabilidades sociais (Ibid., p. 221).
\end{abstract}

A BNCC aponta que a matemática assume um papel fundamental de inclusão do sujeito, a partir de uma reflexão sobre sua cidadania e seu protagonismo na conscientização do direito de aprender. Ainda sobre o direito de aprender a BNCC coloca o estudante como elemento responsável por sua própria aprendizagem.

Assegurar que todos os docentes da educação básica possuam formação específica de nível superior, obtida em curso de licenciatura na área de conhecimento em que atuam é o que preconiza a BNCC com o cumprimento da meta 7 do Plano Nacional de Educação-PNE (2014-2024), assim como a melhoria da qualidade da Educação Básica, e ainda, sobre a meta 15 do PNE, que propõe a garantia de política nacional de formação dos profissionais da educação no que se refere ao Art. 61 da Lei no. 9.394/96 (BRASIL, 1996)

As evidencias são visíveis, nos resultados das edições das avaliações externas, seja em âmbito local, nacional, seja em esfera internacional, a falta de domínio dos conteúdos por parte de alguns estudantes - especificamente aos estudantes dos anos iniciais do ensino fundamental - gera uma aprendizagem de matemática repleta de falhas conceituais, lacunas (SANTOS \& MATOS, 2017). 
É com esse entendimento que se procura compreender em que medida os objetos de conhecimento da BNCC, atendem com qualidade a área de matemática, nos anos iniciais do ensino fundamental, com foco no currículo, na formação docente e nas avaliações internas e externas. A sociedade e os educadores demonstram preocupação com a [re] organização curricular, e a estruturação de uma Base Nacional Comum Curricular (BNCC), pois:

Pensar no currículo é primordial porque é parte de uma tradição seletiva, da visão de algum grupo acerca do que seja conhecimento legítimo e tudo isso está diretamente relacionado à maneira como o domínio e subordinação são produzidos e alterados (APPLE, 2002, p.60).

O currículo direciona a vida dos sujeitos que é relevante e de imenso significado para a comunidade escolar, pois dependendo de como os conhecimentos são organizados, apresentados, tem o poder de nortear, mudar ou parar a vida dos discentes e docentes, uma vez que:

Currículo é o conjunto de estratégias para se atingir as metas maiores da educação. O currículo tem como componentes solidários objetivos, conteúdos e métodos. O solidário significa que não se pode alterar um dos componentes sem que se alterem os outros dois (D'AMBROSIO, 2011, p. 11).

As políticas públicas que envolvem o currículo escolar, e as implicações dessa discussão em nível nacional, mais efetivamente a partir da promulgação da Lei de Diretrizes e Bases da Educação (LDBEN) №. 9.394/96 ganham maior força e adesão com a Lei n. .13 .005 , de 25 de junho de 2014, que promulga o Plano Nacional de Educação-PNE (BRASIL, 2014).

O currículo perpassa o limite da seleção política, de conteúdos considerados válidos, de comportamentos considerados necessários a partir de regras postas em documentos oficiais, considerados importantes, e que são elaborados em um determinado momento histórico, carregado de ideologias. O currículo pressupõe uma visão de superação de algo que deve ser formal, cumprido no âmbito escolar, mas que deve estar em constante construção/reconstrução para atender às necessidades do sujeito (FREIRE, 1987).

Os conteúdos apresentados na BNCC são organizados visando as muitas possibilidades de aparelhamento do conhecimento escolar em unidades temáticas, e cada unidade temática contempla um leque (maior ou menor) de objetos de conhecimento. 


\section{Considerações Finais}

O conhecimento matemático é concebido como útil à sociedade, sendo frequentemente utilizado em diversos setores como no campo da ciência e da tecnologia. Conceitos e modelos matemáticos atuam na sociedade como parâmetros que controlam e estimulam, influenciando a vida do cidadão, tais como, uma sigla ou índice qualquer definido como uma função matemática, maneiras de calcular impostos, salários e inflação. Essas aplicações permitem vincular a matemática na sociedade como um conhecimento indispensável. Ao mesmo tempo, dados estatísticos e resultados matemáticos também se apresentam como referências constantes na sociedade, sobretudo, quando apresentados como suportes estruturais de argumentação e convencimento.

As reformas curriculares historicamente, sempre foram cenário de muitas disputas, todavia faz-se relevante compreender que as mudanças no ensino deve promover a reforma do pensamento. $E$ isso no mundo contemporâneo exige entender e documentar as inúmeras formas na qual as políticas educacionais são colocadas em ação nas escolas.

No que se refere ao currículo de matemática, envolvendo os objetos de conhecimentos e os direitos de aprendizagem, os docentes devem permanecer em luta pelo reconhecimento de um currículo, que não represente apenas a seleção de conteúdos, mas que seja uma construção cultural do sujeito, para o sujeito - na escola, num movimento de transformação do saber científico em saber escolar, com sentido na/para realidade desse sujeito.

Por toda essa necessidade de contínua discussão sobre o currículo, as reformas curriculares não cessam com a BNCC, mas esse documento inaugura uma nova era nas escolas básicas que incluem repensar a forma de ensinar e aprender, com implicações na formação docente, tendo em vista que é a primeira vez na história do Brasil que se elabora um currículo nacional de base comum.

\section{Referências}

APPLE, M. Manuais e trabalho docente. Lisboa: Didáctica Editora, 2002

BERTI. A. A corporeidade no espaçotempo escolar: uma possibilidade na construção rizomática do conhecimento. [s.l]: [s.e], 2009.

BICUDO, I. M. T. Um educador de corpo inteiro. BOLEMA. Rio Claro: UNESP, 2000. 
BRASIL. Secretaria de Educação Fundamental. Parâmetros curriculares nacionais: matemática.Secretaria de Educação Fundamental. - Brasília: MEC/SEF, 1997.

BRASIL. Constituição da República Federativa do Brasil de 1988. Brasília: Supremo Tribunal Federal, Secretaria de Documentação, 2017

CARNEIRO, L, N. S. Aprendizagem da Matemática: Dificuldades Para Aprender Conteúdos Matemáticos Por Estudantes do Ensino Médio. UFPCUC. Pará, 2018.

CANIVEZ, P. Educar o cidadão? Trad. E. dos S. Abreu \& C. Santoro. Campinas: Papirus, 1991.

CURY, C.R.J. A Educação Como Desafio na Ordem Jurídica. In: LOPES, Eliane Martha Teixeira; FARIA FILHO, Luciano Mendes de; VEIGA, Cynthia Greive. 500 anos de educação no Brasil. Belo Horizonte: Autêntica, 2000

D'AMBROSIO, U. Globalização e Multiculturalismo. Blumenau, SC: FURB, 2011. GATTI, B.A. Pesquisa em educação e formação de professores. Coleção formação do professor. Curitiba: Champagnat, 2010.

MARTINS, R. A evolução no ensino da matemática e a importância de se conhecer sua história. São Paulo: Revista Científica Multidisciplinar Núcleo do Conhecimento,2009

MIRANDA, M. G. A organização escolar em ciclos e a questão da igualdade substantiva. Goiás: Revista Brasileira de Educação, 2003

MIORIM, M. A. Introdução à história da educação matemática. São Paulo : Atual, 1998.

MOL, R. S. Introdução à história da Matemática. Belo Horizonte: CEAD - UFMG, 2013.

PIRES, C.M.C. Currículos de Matemática: da Organização Linear à Idéia de Rede. São Paulo, SP: FTD, 2000.

ROCHA, I.C.B. Ensino de Matemática: Formação para a Exclusão ou para a Cidadania?. In: Educação Matemática em Revista. São Paulo: SBEM, 2001

VALENTE, J.A. Aprendizagem por computador sem ligação à rede. In: LITTO, Predric; FORMIGA, Marcos (Orgs.). 0 estado da arte. São Paulo: Pearson Education do Brasil, 2008.

VAMPRÉ, S. Memórias para a história da Academia de São Paulo. São Paulo: Editora Saraiva, 1924. 